\title{
Differentiation of Biocides and Cleaning Agents - Where is the Boundary?
}

\begin{abstract}
Dieter Drohmann and Lara Dickens*
The EU Biocidal Products Regulation (BPR) regulates the placing on the market and use of biocidal products. Biocidal products require an authorisation before they can be placed on the market. The active substances contained in the biocidal product must be approved beforehand. Questions repeatedly arise about the distinction between biocides and cleaning agents/detergents and about certain labelling obligations. In particular the question of how products are claimed and marketed, and which factors may lead to a cleaning product having to be authorised as a biocide under the BPR. Due to a lack of clarity in the regulations and the non-availability of guidelines, especially in borderline areas, this article attempts to differentiate between cleaning agents and a biocide application with a concrete example from the pulp and paper industry and to illustrate which circumstances are relevant.
\end{abstract}

\section{Introduction}

The Biocidal Products Regulation (BPR, Regulation (EU) 528/2012) ${ }^{1}$ concerns the placing on the market and use of biocidal products, which are used to protect humans, animals, materials or articles against harmful organisms such as pests or bacteria, by the action of the active substances contained in the biocidal product. This regulation aims to improve the functioning of the biocidal products market in the European Union (EU), while ensuring a high level of protection for humans and the environment. All biocidal products require an authorisation before they can be placed on the market, and the active substances contained in that biocidal product must be previously approved. There are, however, certain exceptions to this principle.

Questions have been raised many times concerning the differentiation of biocides versus cleaning agents, as well as certain labelling claims for cleaning products or detergents. Specifically, which types

\section{DOI: $10.21552 / \mathrm{icrl} / 2020 / 2 / 6$}

Dieter Drohmann is CEO of the Chemservice Group. For Correspondence: <d.drohmann@chemservice-group.com>. Lara Dickens is Managing Director of Chemservice UK. For Correspondence: <l.dickens@chemservice-group.com>

1 The Biocidal Products Regulation (BPR, Regulation (EU) $528 / 2012$ ) of claims would require that a cleaning product has to be authorised as a biocide under the EU BPR.

Cleaning products with claims such as those described in this article are generally considered by the regulators not to be intended for a biocidal purpose. These cleaning products claim to remove dirt or other debris and are not aiming to mitigating any harmful organisms.

Under EU BPR in general, a cleaning agent or cleaning product is considered to be intended for a biocidal purpose if, among other things, the person who distributes or sells it claims, states, or implies that the product prevents, destroys, repels or mitigates harmful organisms. Therefore, once a product label (or other statement made in connection with the sale or distribution of the product) includes any claim of bacteria/pest mitigation, the product is one that is intended for a biocidal purpose and becomes subject to the authorisation provisions under the EU BPR.

A product need not act directly on bacteria in order for it to mitigate it and be considered a biocide. For example, claims that a product affects the habitat or food source of a pest/bacteria are considered to be 'mitigation' claims against that pest/bacteria. Such claims are in contrast with statements about a product's use that merely claim to remove dirt or other debris without any relation to mitigating a microorganism, its food source, or its habitat. 
Additionally, the expectation of consumer on the function of the product also plays a role. Furthermore, indication for a biocidal product can be the use of 'classical' biocide ingredient formulations (see BauA Webpage). ${ }^{2}$

Certain products may have effects that mitigate microorganisms without being intended for a biocidal purpose, like deodorizers, bleaches, oxidizers and cleaning agents. They are not considered biocides because they are not intended to prevent, destroy, repel or mitigate bacteria/pests. However, the regulation provides, and regulators consider, that these types of products are not biocides only if no biocidal claim is made on their labelling or in connection with their sale and distribution. In other words, where a claim or implication is made in connection with the sale or distribution of a cleaning product that its use will mitigate a harmful organism, either by itself or in combination with any other substance, the product would be considered to be intended for a biocidal purpose and would therefore be required to be authorised in the EU under the requirements of the BPR.

Please note, that EU BPR requires that efficacy data supports the biocidal claim for the product to be authorised. Insufficient biocidal activity, but still complying with the definition of a biocidal product, will result in rejection of the biocidal product application. These products cannot be allowed on the market as biocides.

This topic has additional complexity because there are substances with antimicrobial properties as well as properties of cleaning agents. These are for example bleaching agents and oxidizers. Moreover, the 'confederational' structure of the European Union in this regard, can result in a situation that different Member States also have different views on the differentiation between a biocide and a cleaning agent.

Due to the absence of clarity in the regulations and the available guidance, this article tries to differentiate between cleaning agent versus a biocidal application in one example of the pulp \& paper industry.

\section{Definitions and Characteristics}

A chemical product may have a number of different functions leading to a variety of commercial uses; where this is the case the definitions given in legislation must be taken into account to establish the ap- propriate regulatory requirements for placing the product on the market for its intended function. The conditions (eg temperature, $\mathrm{pH}$ ) in which a chemical substance is used is often important for it to perform as intended. The legislative definitions and requirements may differ depending on the jurisdiction in which the product is sold, potentially adding to further complexity. In relation to the case described in this article, the main use of the product to consider would be as a cleaning agent and as a biocide or pesticide.

\section{Cleaning Agents}

An EU Regulation ${ }^{3}$ on detergents specifies requirements for detergent products, where a detergent is defined as 'any substance or mixture containing soaps and/or other surfactants intended for washing and cleaning processes'. The regulation also defines cleaning as 'the process by which an undesirable deposit is dislodged from a substrate or from within a substrate and brought into a state of solution or dispersion'. A so-called 'disinfectant' that could be considered to have a cleaning function would fall under the Biocidal Products Regulation since such products are intended for and effective at killing harmful living organisms.

In the United States of America (USA), although not categorically defined, a cleaning agent is considered to be one that removes unwanted substances and can be through the use of a chemical or by mechanical or abrasive action. The US Environmental Protection Agency (EPA) discusses the difference between cleaning agents and pesticides on its website where it states, the term 'cleaning product' means a substance or mixture of substances (such as chemical or biological substances) that is intended to clean away or remove inanimate material from a surface, water or air and that makes no pesticidal claims.'

Separately, there are three groups of antimicrobials (an agent that kills microbial growth) registered by EPA for public health uses: disinfectants, sanitizers and sterilisers. These are defined in the following manner:

2 See, <http://www.reach-clp-biozidhelpdesk.de/de/Biozide/Biozid-Definition/Definition.html>

3 REGULATION (EC) No 648/2004 OF THE EUROPEAN PARLIAMENT AND OF THE COUNCIL of 31 March 2004 on detergents. 
- a disinfectant destroys or irreversibly inactivates infectious or other undesirable organisms, but not necessarily their spores;

- a sanitizer reduces but does not necessarily eliminate all the microorganisms on a treated surface;

- a sterilizer destroys or eliminates all forms of bacteria, fungi, viruses, and their spores.

Both the claim of use on the label and the intended use of the product are important in determining the categorisation in the US and consequently the regulatory requirements. The following section provides more information on pesticide definitions.

\section{Biocides and Pesticides}

In the EU, the Biocidal Products Regulation covers a very diverse group of products, including disinfectants, pest control products and preservatives. Biocidal products are defined in the EU BPR (Article 3) as follows:

- any substance or mixture, in the form in which it is supplied to the user, consisting of, containing or generating one or more active substances, with the intention of destroying, deterring, rendering harmless, preventing the action of, or otherwise exerting a controlling effect on, any harmful organism by any means other than mere physical or mechanical action,

- any substance or mixture, generated from substances or mixtures which do not themselves fall under the first indent, to be used with the intention of destroying, deterring, rendering harmless, preventing the action of, or otherwise exerting a controlling effect on, any harmful organism by any means other than mere physical or mechanical action.

Based on this definition, two main requirements must be met for this Regulation to apply. Firstly, the intended use of the product is to have an effect on harmful organisms (defined as 'an organism, including pathogenic agents, which has an unwanted presence or a detrimental effect on humans, their activities or the products they use or produce, on animals

4 FIFRA implementing regulations of Title 40 of the Code of Federal Regulations (40 CFR) Parts 150.189.

5 See, <https://chemicalwatch.com/102584/south-korea-approvesbiocides-law-and-chemical-act-amendments> or the environment'); and secondly, that that effect is to cease the harmful nature of the organism (destroying, rendering harmless) or to control the harmful nature (deterring, preventing the action, exerting a controlling effect). The definition clearly excludes products causing this effect through physical or mechanical action.

The second indent specifies that substances or mixtures may fall under the scope when they are used in a way that generates a substance or mixture with the purpose of having an effect on harmful organisms (referred to as 'in-situ generated active substances'). This implies that such substances or mixtures may be used for other purposes, without the generation of new substances or mixtures in use and/or although new substances/mixtures are generated in use, the purpose is not to have an effect on harmful organisms. As with the first indent, the intention of the use is fundamental.

A pesticide in the EU is generally regarded as a plant protection product; that is products which are used to control pests, weeds and diseases affecting plants.

In the USA, pesticides are regulated under the Federal Insecticide, Fungicide, and Rodenticide Act (FIFRA $)^{4}$. FIFRA defines a pesticide as, 'any substance or mixture of substances intended for preventing, destroying, repelling, or mitigating any pest'. A pest is defined as, '(1) any insect, rodent, nematode, fungus, weed, or (2) any other form of terrestrial or aquatic plant or animal life or virus, bacteria, or other micro-organism (except viruses, bacteria, or other micro-organisms on or in living man or other animals)'.

There are nuances in the terms used in the US too, where a biocide is specified to be any poison that kills a living organism, whereas a pesticide is a substance intended to control, prevent, or kill a pest. The EPA considers a product to be a pesticide (and require registration) if the person placing it on the market claims or implies that it contains a substance that can be used as a pesticide directly or used to manufacture a pesticidal product. It should also be noted that any product without this claim but has no other commercially viable use other than for pesticidal use would be regarded as a pesticide by EPA.

In South Korea ${ }^{5}$, biocides are defined as, 'Chemical substances, natural substances or organisms that are capable of suppression, removal and control of hazardous organisms'. 
Australia regards the biocidal function as the capability of a substance or mixture of substances to kill living organisms; and thus a biocide as products containing one or more active constituents (or the active constituents themselves) that are supplied to destroy, deter, render harmless, prevent the action of, or otherwise exert a controlling effect on any harmful organism by chemical or biological means.

\section{Examples of Multiple Use Substances}

A multitude of chemical substances exist that have more than one function due to their intrinsic properties, which has resulted in the development of products for a range of commercial uses. Depending on the use (and the resulting exposure to humans and environment), the regulatory requirements may differ. Some examples of such substances are given below.

\section{Citric acid (CAS 77-92-9)}

Naturally occurring in some fruit and vegetables especially citrus fruits, citric acid is a weak acid that is manufactured in large quantities. Citric acid is an example of a substance with a vast number of useful properties, which allows it to be used in a wide range of industries. It is used in food and drink as a flavouring or a preservative. The substance is designated with E number E 330 as an approved additive for human consumption in the EU via its Regulation on Food Additives ${ }^{6}$. In the USA citric acid is listed in the Code of Federal Regulations Title 21 as a direct food substance affirmed as generally recognised as safe (GRAS).

By contrast, it can also kill bacteria and mould making it an effective biocidal disinfectant. Since citric acid is used in the EU as a biocidal active substance, the Biocidal Products Regulation applies when the product is intended to be used in disinfectants and algaecides. In the US, any claim of use as a pesticide means it falls under FIFRA and requires registration by the supplier. Citric acid is also useful for cleaning by removing inanimate materials such as soap scum and limescale. Other industries using citric acid include cosmetics, pharmaceuticals and agriculture. The use of citric acid in cosmetics for example means it must comply with the Cosmetics Regulation ${ }^{7}$ in the EU, with it being listed therein as a preservative allowed in cosmetic products; and in the US application of citric acid in personal care products is overseen by the Food and Drug Administration (FDA) .

\section{Copper (CAS 7440-50-8)}

Copper is an essential micronutrient for all living tissues and is therefore necessary for normal growth of plants and animals. It is used in the agricultural industry; in fertilisers to correct copper deficient soils and in animal feeds for maintaining healthy livestock. Copper and its compounds are used as a biocidal active ingredient, for example in disinfection, wood preservation and for the preservation of water or other liquids used in cooling and processing systems. Copper compounds are also approved for plant protection use, falling under the EU regulation ${ }^{9}$ for such products.

\section{Bleaching Systems / Oxidizer}

Studies ${ }^{10}$ have shown that common bleaching systems used in detergents are bactericidal under laboratory and field conditions, have fungicidal and virucidal effects and thus under certain conditions contribute to hygienisation of the laundry in the low temperature range. Due to the oxidative effect of the bleaching agents, not only are coloured organic compounds oxidized, but other organic compounds and organisms, eg undesirable odorous substances, can also be eliminated by this method. A further positive side effect is the reaction of the bleaching agents with microorganisms to possibly kill them.

Oxidative bleaching agents or bleaching systems are an important component of many washing and

6 REGULATION (EC) No 1333/2008 OF THE EUROPEAN PARLIAMENT AND OF THE COUNCIL of 16 December 2008 on food additives.

7 REGULATION (EC) No 1223/2009 OF THE EUROPEAN PARLIAMENT AND OF THE COUNCIL of 30 November 2009 on cosmetic products.

8 https://www.fda.gov/

9 REGULATION (EC) No 1107/2009 OF THE EUROPEAN PARLIAMENT AND OF THE COUNCIL of 21 October 2009 concerning the placing of plant protection products on the market and repealing Council Directives 79/117/EEC and 91/414/EEC.

10 Betz, M. (2001): Antimikrobielle Wirksamkeit von Bleichmitteln und Bleichsystemen.- Dissertation, Technische Universität München. 
detergent formulations (eg powdered universal detergents, machine dishwashing liquid). In the cleaning process the bleaching agents have the task of removing coloured to permanently eliminate soiling that cannot be removed by other formulation components.

During the bleaching process the chromophoric groups are chemically oxidized in such a way that due to the oxidative degradation of these compounds, smaller molecules result, which are easier to wash out. Depending on different washing habits globally, two oxidative bleaching processes for laundry in private households is of importance: the 'Active chlorine bleaching' with inorganic active chlorine compounds such as sodium hypochlorite and the 'Active oxygen bleaching' with active oxygen compounds.

Sodium hypochlorite (NaOCl, CAS 7681-52-9) forms hypochlorous acid in water, which, due to its high oxidation potential can cause a bleaching reaction. The active bleach hypochlorite solution consists of hypochlorite anions (ClO-), chlorine $\left(\mathrm{Cl}_{2}\right)$ and hypochlorous acid ( $\mathrm{HOCl}$ ). Under European washing conditions, hydrogen peroxide-based bleaching is the dominant bleach. Because of its low stability, hydrogen peroxide is not used in detergents directly, but mostly in the form of inorganic per-salts. For reasons of safety, good storage stability and protection of colours and fabrics, percarbonate as bleaching agent in detergents has the largest commercial significance.

Please note that beside their use in detergents both Hydrogen peroxide and Sodium hypochlorite are authorized as biocides (or their precursors) under EU BPR. According to the ECHA website, the use of Sodium hypochlorite in non-biocidal applications under $\mathrm{REACH}^{11}$ is in the volume band of up to 1 Mio tonnes per year in non-intermediate applications. Among many others, registered uses include:

- Industrial Use in Pulp \& Paper

- Industrial \& Professional Cleaning

- Industrial Use in Sewage \& Cooling or Heating Water

- Water Treatment Chemicals

11 Regulation (EC) No 1907/2006 of the European Parliament and of the Council of 18 December 2006 concerning the Registration, Evaluation, Authorisation and Restriction of Chemicals (REACH)

12 Duggirala (2005): Formation of Calcium Carbonate Scale and Control Strategies in Continuous Digesters.

13 Woodward \& Stoner (2011): Deposit Analysis - Investigating Microbial Problems in a Paper Machine Environment. In: PaperCon 2011, p. 2063-2064.
- Industrial Use in Textile Treatment

- Consumer Use in Washing \& Cleaning

- Consumer Use for Bleaching

\section{The 'Deposit Control Case' in the Paper Industry}

The authors were involved in a review of an innovative deposit (scale) control technology to continuously assure clean paper machine systems.

The pulp and paper industry is one of the heaviest users of water, which is used in nearly every part of the manufacturing process. Accumulation of scale is a phenomenon that can occur in all pulp and paper making processes. This occurs even with the purest water and state-of-the art water treatment. The scale deposits can cause a number of operational problems such as plugging of equipment, inefficient usage of chemicals, increased utility costs, lost production due to downtime, and downgraded products from increased dirt counts. Scale occurs when inorganic salts, such as calcium carbonate, calcium oxalate, calcium sulfate and barium sulfate, precipitate from pulp/paper making process waters to form a deposit on system surfaces ${ }^{12,13}$. Scale is defined as hard mineral coatings and corrosion deposits made up of solids and sediments that collect on or in distribution system piping, storage reservoirs and household plumbing. Scaling, which is the deposition of mineral solids (including organics from use of starches, glues, etc.) on the interior surfaces of water lines and containers, most often occurs when water containing carbonates or bicarbonates of calcium and magnesium is heated. Scale that has accumulated from one type of component can form an excellent base for other scales to grow on. For example, calcium carbonate scale on 'black liquor evaporators' in a paper mill is often comprised of other scales such as sodium carbonate and burkeite (double salt of sodium sulphate and sodium carbonate). Common scales are calcium carbonate $\left(\mathrm{CaCO}_{3}\right)$, barium sulphate $\left(\mathrm{BaSO}_{4}\right)$, alumina $\left(\mathrm{Al}[\mathrm{OH}]_{3}\right)$ and Calcium Oxalate $\left(\mathrm{CaC}_{2} \mathrm{O}_{4}\right)$. Several mechanisms for scale formation have been hypothesized, but the main one is based on exceeding solubility limits of the scale components. Thus, if we consider the formation of calcium carbonate or oxalate scale it can be deduced that the scale formation follows a sequence of events. The initiating step, called nucleation, involves adsorp- 
tion of the scale components onto a surface. As the concentration of ions in the bulk phase of the solution increases, the adsorption process continues until ion clusters begin to form on the surface. The ion clusters eventually grow to a critical size and become stable enough to remain on the surface, usually at imperfections or rough locations on the surface itself.

Once nucleation has occurred, the rate of scaling is accelerated. Scale growth, also called crystallization, can propagate via two ways, namely, ion by ion or nucleus by nucleus. Ion by ion growth occurs as ion clusters continue to be adsorbed by the existing nuclei on the surface. Such a mechanism typically leads to formation of a smooth scale. In nucleus to nucleus growth, nuclei are formed in the bulk phase of the solution prior to their attachment to the surface nuclei. These nuclei are larger in size than ion cluster and consequently build-up a rougher, imperfect scale on the surface. In addition, any crystals that are formed in solution may also become entrapped within the rapidly growing scale matrix resulting in a mixed deposit scale. The inverse relationship of temperature to solubility implies that areas of high temperature are particularly prone to scale deposition. Temperature can also cause formation of noncrystalline scale because heat has a tendency to bake deposits in place. Once baked in place, sludge deposits can be as troublesome as scale ${ }^{14}$.

The scaling process is controlled by four critical parameters: cation concentration (eg, calcium), anion concentration (eg, carbonate), $\mathrm{pH}$ and temperature. The solubility product of the cation/anion product affects the precipitation of scale, $\mathrm{pH}$ of the bulk solution determines the form of the various species contributing to scale. For example, carbonate dissolves in acid solution and precipitates under an alkaline environment. Temperature displays a positive correlation with the rate of nucleation.

In order to ensure a failure-free process in paper mills and to prevent built-up of scaling, a complex cleaning agent product has been invented, which includes scale inhibitors, dispersants, alkali and an oxidizing agent. This new cleaning agent product prevents the built-up of scale and keeps the inorganic salts in suspension or solution. Sodium hypochlorite (CAS 7681-52-9) has proven to be the suitable oxidizing agent.

Between 2009 - 2013 a case study was conducted to demonstrate the applicability and practicability of the new cleaning system. A paper plant was selected which had frequent paper sheet breaks. Deposits can grow to a critical layer thickness, until they peel off and form holes, spots and paper breaks. A brominebased biocide (BCDMH, CAS 16079-88-2) was dosed to prevent deposits caused by filamentous bacteria, with the result that they no longer occurred. The ATP results ${ }^{15}$ and the bacterial counts lead to the conclusion, that microbiological treatment was sufficient. However, the new monitoring system could clearly identify that special paper grades lead to increased deposit (scale) forming, for instance due to increased starch and sizing agent (eg Alkenyl Succinic Anhydride) use; and that the microbiology is not the route cause but that high starch and sizing concentrations applied caused the deposit problems. After the application of the new cleaning system (in addition to $\mathrm{BCDMH})$, the following results could be shown:

- Increased removal of existing deposits occurred;

- Number of sheet brakes decreased dramatically from 45 to 15 per month;

- No more deposits found in head boxes;

- No impact on water sewage plant occurred;

- Treatment costs below the former treatment concept;

- No boil-outs required anymore;

- New cleaning system forms a very small amount of $\mathrm{COD}^{16}$.

The ingredients of the cleaning system include additives used as hardness stabilizers, wetting agents, oxidizer, surfactants and crust inhibitors.

The use of this new cleaning technology is neither marketed or presented as a biocidal product nor is the mixture a 'classical' active biocide ingredient formulation. Merely, the component 'sodium hypochlorite' $(\mathrm{NaOCl})$ has in certain applications a biocidal function, as well as other uses and applications (eg bleaching agent, anti-scaling agent, functional fluid, oxidizing/reducing agent, plasticizers, processing aid, solvent) such as in the present case as an antiscaling agent. When dissolved in water it is commonly known as a bleaching or liquid bleaching agent. Sodium hypochlorite is practically and chemically

14 Sitholé (2002): Scale deposit problems in pulp and paper mills.

15 The ATP test is a process of rapidly measuring actively growing microorganisms through detection of adenosine triphosphate (ATP).

16 Chemical Oxygen Demand. 
distinct from chlorine. It is a compound that can be effectively used for water purification. It is used for bleaching, odour removal and water disinfection (a biocidal use). Due to its strong oxidizing capacity, Sodium hypochlorite has scale removal properties. The use of Hypochlorites as anti-scaling agents or scale removers is commonly described in literature. $^{17,18,19,20}$

When sodium hypochlorite is dissolved in water, the resulting solution is quite basic due to the production of $\mathrm{OH}-$ ions by the following reaction: $\mathrm{NaO}-$ $\mathrm{Cl}(\mathrm{s})+\mathrm{H}_{2} \mathrm{O}(\mathrm{l}) \rightarrow \mathrm{HOCl}(\mathrm{aq})+\mathrm{NaOH}(\mathrm{aq})$. If the $\mathrm{pH}$ of the water is too low $(\mathrm{pH}<6.0)$, chlorine will escape as a gas, decreasing the anti-scaling effectiveness and increasing equipment corrosion. If chlorine is added to an alkaline water $(\mathrm{pH}>8.5)$, the amount of hypochlorous acid formed will greatly be reduced, and the water will not be disinfected. Since different amounts of hypochlorous acid are present in the solution as a function of the $\mathrm{pH}$ value, the disinfection result is better in the weakly acidic $\mathrm{pH}$ range than in the alkaline range, which has been confirmed in numerous investigations (WALLHÄUßER, 1995 ${ }^{21}$; COTTER et al., $1985^{22}$; DEATH and COATES, $1979^{23}$; TRUEMAN, $1971^{24}$. Thus, the effectiveness of sodium hypochlorite, as either a disinfectant or an antiscaling agent, is strongly dependent not only on the concentration, but also on the $\mathrm{pH}$ value. The $\mathrm{pH}$ dependency of $\mathrm{NaClO}$ is described in detail in the literature, eg in MORRIS J.C., $1966 .^{25}$

$\mathrm{NaOCl}$ is also used in dentistry. While the substance has antimicrobial activity in the $\mathrm{pH}$ range of 6.0-7.5, dead tissue is destroyed predominantly in the

17 US Patent No. US6291411 B

18 Willmott \& McCarthy (2001): TPM - A Route to World Class Performance.

19 US Patent No. US20050187120 A1

20 US Patent No. US7410938 B2

21 Praxis der Sterilisation, Antiseptik und Konservierung: Qualitätssicherung der Hygiene in Industrie, Pharmazie und Medizin.

22 Cotter JL, Fader RC, Lilley C, Herndon DN (1985) Chemical parameters, antimicrobial activities, and tissue toxicity of 0.1 and $0.5 \%$ sodium hypochlorite solutions. Antimicrob Agents Chemother 28:118-122.

23 Effect of $\mathrm{pH}$ on sporicidal and microbicidal activity of buffered mixtures of alcohol and sodium hypochlorite. In: J Clin Pathol. 1979 Feb;32(2):148-52.

24 Russell \& Ditchett (2006): Encyclopedia of Environmental Science and Engineering, $5^{\text {th }}$ Edition, Disinfection, 2006, $224-243$.

25 The Acid lonization Constant of $\mathrm{HOCl}$ from 5 to $35^{\circ} \mathrm{C}$. In: J. Phys Chem, 70, 3798 region of higher $\mathrm{pH}$ values (>7.5), ie organic impurities are removed (Mercade et al. ${ }^{26}$ ). The study concludes that Bactericidal activity of $\mathrm{NaOCl}$ solution is enhanced by weak acidification at $\mathrm{pH}$ 6.5. On balance, Sodium Hypochlorite's efficacy as a disinfectant works best at $\mathrm{pH}$ ranges of $6.0-7.0$ and not at the typical alkaline papermaking $\mathrm{pH}$ value. The use of $\mathrm{NaOCl}$ in the newly developed cleaning system takes place at a $\mathrm{pH}$ levels which are much too high for anti-microbial use. As a result, if operating at $\mathrm{pH}$ values $>7.5, \mathrm{NaOCl}$ is not efficiently working as a microbial disinfectant (biocide) and therefore too high doses would be required to deploy a biocidal efficacy. However, use in excess would result in higher release of available chlorine and thus, an increase of corrosion of the equipment. ${ }^{27,} 28,29$

Moreover, disproportionate use of $\mathrm{NaOCl}$ results in significant increase of $\mathrm{AOX}^{30}$ values in the water due to reaction of the chlorine with organic matters, giving rise to organic chlorine compounds such as AOX (halogenated organic compounds absorbable on activated carbon), which are toxic for aquatic organisms and are persistent environmental contaminants. $31,32,33$

Chemically, bromine is closely related to chlorine as they are both halogens and next to each other in the periodic table. As a result, bromine can be used as an alternative disinfectant to chlorine, however there are some key differences. Compared to chlorine, bromine is more stable at high temperatures and a more effective sanitizer at higher $\mathrm{pH}$ levels. For example, at a pH of 8 just over $20 \%$ of chlorine is available as hypochlorous acid whereas more than

26 Mercade M, Duran-Sindreu F, Kuttler S, Roig M, Durany N: Antimicrobial efficacy of $4.2 \%$ sodium hypochlorite adjusted to $\mathrm{pH} 12,7.5$, and 6.5 in infected human root canals, Oral Surgralmedical Pathol Oral Radiol Endod 2009, 1 07: 295-298

27 Memarzadeh (2005): Stainless Steel Trap Corrosion.

28 Arthur H. Tuthill et al. (1998): Effect of Chlorine on Common Materials in Fresh Water.

29 Cantor et al. (2000): THE EFFECT OF CHLORINE ON CORROSION IN DRINKING WATER SYSTEMS.

$30 \mathrm{AOX}=$ Absorbable Organic Halogens

31 Scientific Committee on Health and Environmental Risks (2008): Risk Assessment Report on Sodium Hypochlorite Environmental Part.

32 Emmanuel. Al. (2004): Toxicological effects of disinfections using sodium hypochlorite on aquatic organisms and its contribution to AOX formation in hospital wastewater. In: Environment International 30 (2004) 891-900.

33 EU Risk Assessment Report - Sodium Hypochlorite, 2009. 
$80 \%$ of bromine is available as hypobromous acid. Furthermore, in environments where ammonia is present, bromine will continue to provide disinfection even after it reacts with ammonia to form bromamines, since bromamines are unstable and will revert to hypobromous acid. For these reasons bromine is effective for applications such as microbiological control in cooling towers with $\mathrm{pH}$ in the 7.5 to 9.0 region. Therefore, biocides/disinfectants of choice at $\mathrm{pH}$ levels $>7$ are bromine compounds, since they have a 4-5 times higher efficiency compared to $\mathrm{NaOCl}^{34}$ Bromine is also more biocidal at higher $\mathrm{pH}$-values than chlorine, because $\mathrm{HOBr}$ ionizes to a lesser degree than $\mathrm{HOCl}$. When the $\mathrm{pH}$ value is between 7 and 8.5 dibromoamine (CAS 14519-03-0) is the most common form of bromine used. Dibromoamine is almost as effective as free chlorine in killing microorganisms. Dibromoamine is very active and usually dissociates quickly into bromide ions. Because of this, no bromine remains in the water. The most important bromide substances used as a biocide are sodium bromide (in situ activated with $\mathrm{HOCl}$ ) and BCDMH.

The EU's Manual of Decision on Biocidal Products $^{35}$ states an example under Chapter 2.6. In case the concentration of a substance (with biocidal and cleaning properties) is low, it should be considered as an additive with primary cleaning function, the secondary function is the anti-microbial activity.

\section{Conclusions}

Cleaning products used solely for cleaning without any biocidal intention and biocidal claim are not considered to fall under the scope of the BPR. For cleaning agents, which have intrinsic properties required for the primary use as an oxidizer, but having as well a secondary microbial effect - the primary effect is relevant.

Moreover, biocidal products need to have sufficient antimicrobial activity, otherwise they will not be authorized as biocidal products due to lack of efficacy.
Additionally, biocidal products are characterized by the fact that they are used in typical formulations.

Sodium Hypochlorite's efficacy as a disinfectant works best at $\mathrm{pH}$ ranges of $6.0-7.0$ and not at the typical alkaline papermaking $\mathrm{pH}$ value. Therefore, an additional biocide (eg bromine-based) needs to be used to control microbial growth. The formulation of the cleaning agent does not display a typical biocidal product mixture nor is the product claimed as a biocide, rather is advertised and labelled as a cleaning agent product.

On balance and according to our assessment, this cleaning agent system is not considered to be a biocidal product.

However, the use of the components included in the cleaning agent product needs to comply with REACH requirements if marketed in the EU. Therefore, all uses of this cleaning agent (eg in pulp \& paper production) needs to be covered by the Chemical Safety Assessment and included in the Chemical Safety Report - in case the substances are classified (eg Sodium hypochlorite). The formulator of the cleaning agent system also needs to source REACH registered substances, if no own registration is available and substances are not exempt.

Finally, the cleaning agent product must be notified according to Article 9 of the European Regulation on Detergents. The requirements have been implemented into national legislation, which partly specifies these requirements in more detail. For example, Article 10 of the German Detergent and Cleaning Agents Act (Wasch- und Reinigungsmittelgesetz) stipulates notification obligations for detergents and cleaning products that are not classified as hazardous.

34 See, <https://iccontrols.com/bromine-chemistry-for-disinfection/>

35 MANUAL OF DECISIONS FOR IMPLEMENTATION OF DIRECTIVE 98/8/EC CONCERNING THE PLACING ON THE MARKET OF BIOCIDAL PRODUCTS (Last modified: 21.12.2011). Please note that this document has been withdrawn in 2015 but is still used as a reference document and available on the EU Commission website: see, <https://circabc.europa.eu/faces/jsp/extension/wai/navigation/container.jsp> 